\title{
BRAZILIAN SOCIETY OF CARDIOVASCULAR SURGERY / 2003
}

\author{
Professor Dr. Jarbas J. Dinkhuysen*
}

$\mathrm{T}$ he scenario that dominates our specialty currently deserves important analysis and considerations. There is no doubt that we are living through moments of great conceptual modifications that can and should foretell new conducts and directions, not only for the cardiovascular surgeon but also for the society that represents them.

Recently, in the Society of Thoracic Surgeon (STS) Congress that took place in January 2003 in San Diego, USA, we had the opportunity to verify the worries that are dominating the thoughts of American cardiovascular surgeons. Among them there is no fear in confirming the enormous advances related to profound heart failure at a ultra-structural level that create opportunities for the appearance of more specific and efficient therapies that, in the majority of cases, delay the need for or even avoid previously indisputable indications for surgery.

The great impact that percutaneous interventions have provoked in the day-to-day of surgeons also deserves mentioning affecting the honoraria of surgical coronary artery bypass grafting in the USA (figure 1).

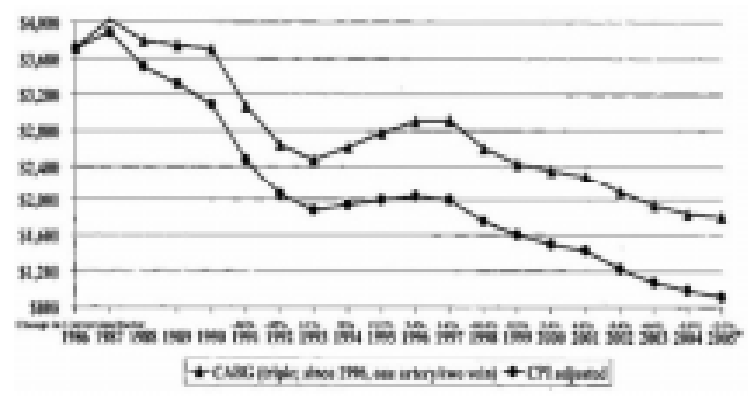

Fig 1. - Cumulative Reductions in Medicare "Allowed Charges” for Coronary Artery Bypass Surgery, 1986-2005* (with \& without CPI adjustment)

$\triangle$ Current Dollars:

O Adjusted to 1986 Dollars to reflect changes in the Consumer Price Index (buying power)

* 2004, \& 2005 projected under current law

A significant tendency in the reduction of charges has been seen, which associated with a drop in the volume of operations, has provoked damaging manifestations for the American surgeons, causing the majority of specialist journals to approach this subject in their editorials.

Here in Brazil, it can be seen that the percutaneous interventions are increasing according to the data of the National Central Register on Coronary Interventions - CENIC (1997-2001) (table 1).

Table 1. CENIC Registry 1997 - 2001

Percutaneous Coronary Interventions in Brazil ( $\mathrm{N}=83,312$ Pts)

\begin{tabular}{ccrcc}
\hline $\begin{array}{c}\text { PCI } \\
\text { Year }\end{array}$ & POBA & Stent & Other & $\begin{array}{c}\text { Total } \\
\text { (Treated Pts) }\end{array}$ \\
\hline 1997 & 7,447 & 5,944 & 184 & 13,575 \\
1998 & 6,687 & 8,376 & 130 & 15,193 \\
1999 & 6,286 & 10,410 & 145 & 16,841 \\
2000 & 5,458 & 17,092 & 78 & 22,628 \\
$2001^{*}$ & 2,333 & 12,702 & 40 & 15,075 * \\
Tetal & 29,211 & 54,524 & 577 & $\times 3,312$ \\
\hline
\end{tabular}

* included until 08/31/01

(Data supplied by Dr Amanda G. M. Rego Sousa)

Additionally the number of coronary arteries treated has also increased with ever-improved results where the stents are proving to be the ideal technique of percutaneous interventions; notably those lined with drugs (table 2), (Figures 2, 3).

Tabela 2. CENIC Registry 1997 - 2001 "Percutaneous Coronary Interventions in Brazil" ( $N=100,806$ Vessels)

\begin{tabular}{ccccc}
\hline $\begin{array}{c}\text { PCI } \\
\text { Year }\end{array}$ & POBA & Stent & Other & $\begin{array}{c}\text { Total } \\
\text { Oreated Yersels) }\end{array}$ \\
\hline 1997 & 8,657 & 7,135 & 208 & 16,000 \\
1998 & 7,762 & 10,161 & 147 & 18,070 \\
1999 & 7,340 & 13,160 & 177 & 20,677 \\
2000 & 6,339 & 21,216 & 112 & 27,667 \\
$2001^{*}$ & 2,708 & 15,634 & 50 & $18,392 *$ \\
Tetal & 32,806 & 67,306 & 694 & 100,806 \\
\hline
\end{tabular}

* included until 08/31/01 


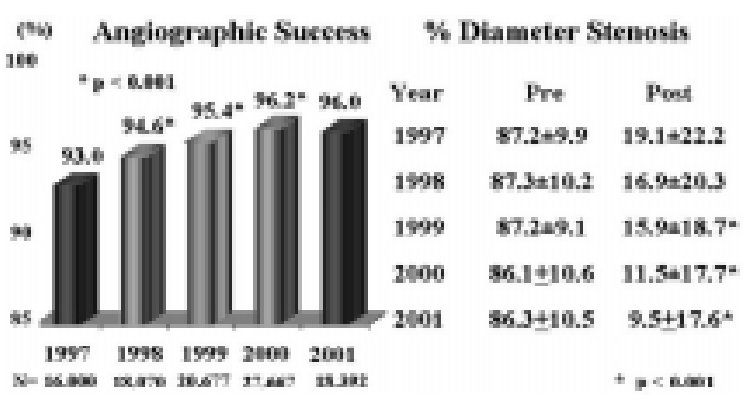

Fig 2. CENIC Registry : PCI in Brazil 1997 - 2001 "The Influence of Stent Implantation on the Immediate Outcome $(N=100,806$ Treated Vessels)

(Data supplied by Dr Amanda G. M. Rego Sousa)

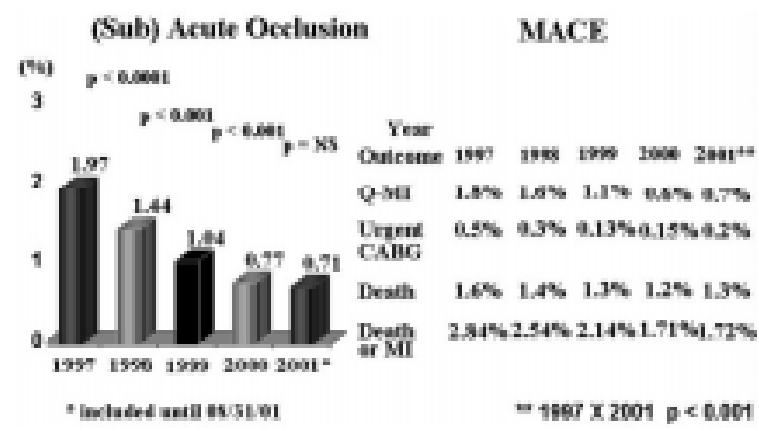

Fig. 3 - CENIC Registry : PCI in Brazil 1997 - 2001

The Influence of Stent Implantation on the Immediate Outcome

(Data supplied by Dr Amanda G. M. Rego Sousa)

The advances of percutaneous therapy in the treatment of coronary atherosclerotic disease is indisputable and irrefutable, and it is the gold-standard for cases of acute myocardial infarction, where its effects have changed the history of this devastating disease. In the area of chronic obstructive coronary disease, the early and short-term results are unquestionable and brilliant. Nevertheless, over the long-term there are persistent doubts for the surgeons mainly relating to local and systemic inflammatory reactions that a stent can provoke, according to the pertinent observations of Dr Renu Vermani from Washington, USA. On the other hand, patients who undergo percutaneous interventions and who later require revascularization of arteries with stents are not infrequent in our field, which this is probably due to the indiscriminant application of this method without adequate selection of the cases.

It is also necessary to call the attention to percutaneous interventions in congenital defects such as aortic restriction, arterial canal persistence, valvar pulmonary stenosis, interatrial communication, interventricular communication, mitral and aortic stenosis and also atrioventricular valve failure, without forgetting heart and associated stimulation have been influenced.
Analyzing the data supplied by the Cardiac tertiary hospital system - Hospital production of Brazil - SICV (Table 3), there is a tendency in the rapid increase of surgical procedures (CABG) maintaining stability, in spite of advances of the percutaneous interventions, on the contrary to what is happening in the USA.

Tabela 3. High Complexity System in Hospital Cardiological Production in Brazil - SICV

TOTAL SURGERIES PER YEAR
One of the plausible explanations for this phenomenon is the great-repressed demand of the patients that did not have access to high complexity treatment, and were thus excluded.

A simple reasoning would be to compare the number of coronary surgical interventions (about 300,000 annually) performed in the USA that has a population of around 270 millions of people, with those performed in Brazil (approximately 26,000 annually) with a population of 170 millions of inhabitants. Within this proportion, if there was no repressed demand, no less than 188,000 operations annually would have been required. In conclusion, in Brazil only $15 \%$ of the patients have access to surgical treatment for heart failure because of this reason. To analyze this more profoundly, is deviating from the objective of this editorial.

It is not difficult to imagine that in spite of the advances in percutaneous therapies, the Brazilian cardiovascular surgery teams, in theory, will have, as opposed to the USA, guaranteed surgical activity, for at least the current generations of surgeons. However, this license may lose much of its support in the face of the speed of scientific and technological improvements that, nowadays, are practically daily, as well as the application in Brazil of health policies which contemplate greater access to highly complex treatment and this repressed demand.

The current reality in which the Brazilian cardiovascular surgeon exists in the unwise relationship with the clinical cardiologist, hemodynamic professionals, interventionists, among others observing a clear isolationist behavior. This is probably due to the important advances that have occurred in clinical and interventionist therapeutic areas whilst little has happened in the area of surgery. Faced with this, the surgeons started to play a secondary role in the 
cardiology context, and consciously or not, they accepted this posture.

In spite of this great-repressed demand, the number of hospitals, teams and surgeons has not increased over the last years, and this is due to a restriction in the costs of the procedures, where much lower values than reality have been paid. A great number of hospitals that attend the national health system patients are public or charitable, due to the low remuneration paid by the government which makes tertiary treatment in private institutions unrealistic. An example of this is the municipals' administration policies in which the Health Ministry established a fixed limit to cover the cost of health, in which the criteria are prioritized according to the administrators, frequently prejudicing patients with more complex diseases. On the other hand, the health insurance companies are continually trying to reduce their costs putting excessive pressure on doctor's honoraria and hospital costs.

Conscious of possible new paradigms in the current scenario of the Brazilian cardiovascular surgery it is necessary to know: 1) how to accept a lower surgical volume due to the technological advances in other correlated areas, causing 2) a lower number of tertiary centers.

On account of this fortuitous reality, future planning of the professional is necessary with constant development of strategies adaptable to the changes in the scenario, among which the following are notable:

- sub-specialize with the inclusion and development of multiple technologies including percutaneous;

- exercise basic science and research in the theoretical education and surgical practice;

- guarantee the education of well trained surgeons with multiple functions, suggesting conceptual changes in the medical training and in the residence courses;

- advocate quality and efficiency of treatment with minimal costs;

- focus on the future with constant evaluation and implantation of strategies, maintaining our future in our hands with autonomy and independence.

Nevertheless, the processes of change are, generally, complex. The implementation of actions that express different opinions can create divergences and be contrary to the interest but the heterogeneity of the individuals is the source of new perceptions and, consequently the different options about which paths should be followed. Institutional maturity occurs when listening and reflecting precede planning and action. Planning the structure and functioning of a national institution with history and credibility taking into consideration the different regions and people is a complex task. This initially requires a conciliatory spirit and a deep knowledge of the cause-effect relationships within the organizational dimensions (people, technology, structure and processes), as well as external variables, which are often not subject to our will and that constantly change (legislation, competitors, politics and economic environment). Within the complexity, the balance between the binomials size versus function and inclusion versus complexity should guide the planning, which requires, besides methodology, systems and techniques, leadership, good sense and wisdom so that the greatest asset of the SBCCV can be prioritized: the credibility.

The benefits arising from these actions provide more efficiency, less bureaucracy, better receipt and optimization of the resources and actions resulting in a more solid image of our Society. On the other hand, the harmful aspects refer to the perpetuation of antiquated concepts, utilization of authoritarianism and not of evidence, focussing on personal interest with inflexibility and recipes (with a loss of innovation) and waste of resources.

The SBCCV/2003 is a barely functioning society, without political or economic force whose primordial actions are centralized with an out-of-date statute and without an administrative base.

Its strong points are:

a) scientific activities (RBCCV Congress);

b) Internet site (computerization);

c) Specialist title

Its weak points are:

a) little or no interaction between the national and regional offices;

b) little or no interaction between the national office and departments;

c) nonexistent professional index;

d) little influence on the health policies of the government;

e) Few or not one service offered to the members such as Medical Education Programs and Professional Defense;

f) Out-of-date statutes.

Its main threats are:

a) lack of financial resources

b) lack of political involvement of the majority of the members.

Its main opportunities are:

a) implantation of a Brazilian Cardiovascular Surgery Registry (ReBCCV);

b) to promote greater integration with Brazilian Society of Cardiology and similar departments;

c) to interact and create more solid links with the Health Ministry (SUS);

d) to interact with the media divulging all the information pertinent to the specialty;

e) to create new departments of the SBCCV;

f) to establish new sources of financing;

g) to strengthen paradigms in the relationships with 
the industry.

\section{Analysis of the weak points of the SBCCV: \\ I) Little or no interaction between the National office and Regional Societies}

The immense regional differences in Brazil reflect in the peculiarities of our State Societies, as well as in their relationship with the SBCCV. The interests of each one are, often, distinct, as are the expectations, projects and posture. Modernization of the SBCCV and of the regional societies is nonexistent and thus there is not optimization of the joining of efforts and resources, generating inefficiency and discontentment.

Questions to be responded:

a) What can or should be generalized in this interrelation, which are the general norms in the relationship between the SBCCV and the Regional Societies?

b) What can or should be particularized, should any Regional Society have privileges?

c) The influence of the Regional Societies should continue to be governed according to the current statutes, demanding perfect adaptation to the statutes? d) Should the Regional Societies look for financial independence, in what way can the SBCCV help?

e) What is the best form to obtain greater support from sponsors with benefits for all?

f) Is the union of forces or each one for themselves best?

g) Is it befitting to develop a national policy of action?

\section{II) Little or no interaction between the National office and departments.}

Specialist departments bring together surgeons from areas of common scientific interest. When they do not have their own juridical identity they utilize the national registration of the SBCCV. Some charge annual fees, apart from obtaining other incomes from sponsors, mainly from the industry that in general are the best sponsors of the SBCCV and the Regional Societies.

Question to be answered:

a) What are the main functions of the specialized departments Scientific and/or associative?

b) What is the role of the departments in the scientific activities of the SBCCV?

c) Are the departments with and without their own juridical identity the same?

d) What is the link or norms in the relationship between the departments and the Regional Societies?

e) What are the administrative and financial relationships of the departments?

f) The organizational structure of the departments is adequate, undersized or oversized?

g) Can or should the departments have their own publications?

h) Should the scientific departments hold their own congresses independently, or can they be held as a pre- congress activity in the SBCCV Annual Congress?

\section{III) Nonexistent levels of professionalism.}

The main objective of employing professionals is to unite competence to compromise. Voluntary work often lacks technical preparation. Even when this requisite is present, there is, in general, a lack of commitment. This occurs due to lack of interest or time for the necessary dedication. Occasionally, personal interest can superimpose those of the institution.

On some occasions, several colleagues managed to perform voluntary work in the SBCCV with an excellent level of compromise and competence. However, finishing the administration period, replacement of these colleagues with the same profile and availability necessary for the completion of the tasks was not achieved. For this reason, we are seeking professionals so that the work can be productive, continuously.

The administrative basis of the SBCCV suggested should include:

a) technology / computing

b) financial / accounting

c) events

d) juridical

e) commercial

f) administrative

Questions to be answered:

a) What posts and functions of the SBCCV should be held by professionals?

b) What areas should be totally controlled by professionals?

c) What areas should be partially controlled by professionals?

d) What areas of the SBCCV should have a professional coordinator orientating a volunteer position and vice-versa?

e) What is the ideal level of professionals for the Revista Brasileira de Cirurgia Cardiovascular and for the site of the SBCCV?

IV) Little influence in the policy of the Health Ministry To live in a representative government system and not to count on representatives (lobby) perhaps is the main cause of this weak point of the SBCCV. In general, all the boards of directors with greater or lesser relationships and influence achieve results that more depend on personal actions than institutions. Questions to be answered:

a) Is it worthwhile to have a representative acting together and with compromise with the SBCCV?

b) How can we gain influence and prestige with governors?

c) The work to bring together the SBCCV with governors can or should be made by a board member or by a professional?

d) How to coordinate the Regional Societies, Departments and National Office together with 
government organs?

e) What other actions should be implemented by the SBCCV to increase its prestige and influence with the government?

f) Is the participation of the SBCCV as a permanent member of the specific health policies orientated by the Health Ministry the fundamental objective of the cardiovascular surgeons?

V) Few or not one service is offered to the associates: medical education program and professional defense The principal actions and services of the SBCCV in benefit of the members are:

a) free receipt of the RBCCV

b) access to the site, e-mail and other facilities of the internet.

Questions to be answered:

a) What actions and services should the SBCCV make available to their members and how to finance them?

b) Which organ of the SBCCV should coordinate each of these actions?

c) How to increase and improve the Medical Education Programs?

d) Is the current professional defense is adequate?

e) The RBCCV and the site fulfil their roles and how can they be improved?

\section{VI) The statute of the SBCCV is out-of-date}

Changes in the statute are necessary taking into account that the current situation that dominates horizons as the cardiovascular surgery in Brazil is much different from the past.

Main threats to the SBCCV are:

a) Lack of financial resources to implement projects and actions of interest. The resources originating from the annul fees relative to 745 members with approximately $40 \%$ of non-payers as well as the profit that the congresses generate added are only sufficient for the maintenance of the National office. This includes payment of employees, taxes, meetings of the board of directors and deliberative counsel and eventual expenses significantly limiting the implementation of actions and projects.

b) Lack of political involvement of the majority of the members. There is no defined planning directed towards the members, the actions are always proportional to the happenings and not preventative and this is due to the lack of an administrative base. The establishment of means of electronic communications facilitating the rapid dissemination of information without cost, as well as the establishment of a technical basis for the receipt of opinions online of the members in subjects such as the elections of the board of directors and the statutes of the SBCCV.

c) Interact and create more solid links with governmental organs. The necessity of greater exchange (lobby) is imperative notably with the Health Ministry making available assistance for all that are related with the specialty.

d) Interact with the media divulging goals that ensure quality in the practice of cardiovascular surgery. The definition of standards and rules in the performance of the specialty, risks, results and the late evolution of heart surgery, the costs of the procedures (SUS, health insurance) apart from information and medical counseling, concepts, curiosities and elucidation.

e) Creation of new Departments in the SBCCV whose objective will be to bring together medical and non-medical professionals who invariably cooperate meeting, such as the department of clinical and intensive cardiology, anesthesia, nursing, psychotherapy, physiotherapy, cardiopulmonary bypass and circulatory assistance and bioengineering. f) Establishment of new options for sources of income

- $\quad$ the recently structured site of SBCCV has the possibility of attracting resources from sponsorship of its pages (in preparation);

- Revista Brasileira de Cirurgia Cardiovascular (RBCCV) should be self-sufficient with sponsorship from commercial advertisements;

- $\quad$ Quality seal (ANVISA) by the applicability of input in clinical practice of the specialty by means of multicenter tests coordinated by the SBCCV (project to be implanted);

- Multicenter clinical trials with support from companies or even grant agencies such as FAPESP, CAPES and CNPq (to be implanted);

Optimization of the income resulting from the annual Congress through its (temporary) centralization with anticipation of the costs the companies would have better conditions of sponsorship and other activities of the SBCCV (for the future).

g) Incorporation of new paradigms in the relationships between the SBCCV with the industry

- accept them as a partner and with common objectives with special bias on technological innovations and not as a simple sales relationship;

- $\quad$ work together to supply the necessities for both sides, resolving questions of technological innovations and evaluation of its applicability (ANVISA);

recognize the industry as an important assist in the current scenario, considering the lobbists as of real importance and influence;

- $\quad$ maximize their participation with sponsorship in educational programs (site SBCCV, RBCCV, ReBCCV and annual congress).

Finally I would say that "the SBCCV is of no one, and of all and it is the obligation of its directors to focus their actions with seriousness and credibility in its strengthening so that it can accomplish its greatest mission: the Brazilian Cardiovascular Surgeon”. I 
remember Pablo Neruda when I say:

"Die slowly, those who does not travel, who does not read, who does not hear music, who does not find grace within themselves.

Die slowly, those who destroy their own love, who do not let themselves to help.

Die slowly, those who transform themselves into a slave of habit, repeating everyday the same routines, those who do not move from the mark, do not risk to dress a new color or do not converse with whom they do not know.

Die slowly, those who make the television their guru. Die slowly, those who avoid a passion, who prefer the black over the white and the dots over the 'is' in detriment of a whirlpool of emotions exactly as they recover the brilliance in their eyes, smiles from the yawns, hearts that trip up and feelings.

Die slowly, those who do not turn the table when unhappy in their work, who do not risk the certain for the uncertain to follow a dream, who do not permit at least once in their life to escape from the wise counseling.

Die slowly, those who spend their days complaining about their bad luck of incessant rain.

Die slowly, those who abandon a project before starting it, not asking about an unknown subject, remembering always that life demands a much greater effort than the simple fact of breathing.

Only perseverance will enable us conquer a splendid state of happiness."

President of the Brazilian Society of Cardiovascular Surgery. 